\title{
Feasibility study on production of Metal Matrix Composite (MMC) material for Electrical Discharge Machining (EDM) tools using Rapid Prototyping (RP) technique
}

\author{
S. Shamsudin ${ }^{1}$, and M. A. Lajis \\ Sustainable Manufacturing and Recycling Technology, Advanced Manufacturing and Materials \\ Centre (SMART-AMMC), Universiti Tun Hussein Onn Malaysia, 86400 Parit Raja, Batu Pahat, \\ Johor, Malaysia.
}

\begin{abstract}
In common practice, tools for EDM have traditionally been made by machining copper or graphite to the required profile using $\mathrm{CNC}$ machines. Increasing the degree of complexity of any tooling design for any operations results in a corresponding increase in time and cost required. With the advent of rapid prototyping techniques, the problem of making tools with complex shapes becomes much simpler and easy. The main aim of this research was to develop new EDM electrode material through a novel approach by rapid prototyping (RP) technique. In this study, the potential application of copper $(\mathrm{Cu})$ reinforced alumina $\left(\mathrm{Al}_{2} \mathrm{O}_{3}\right)$ fabricated with various compositions as an EDM electrode was investigated. The electrodes were fabricated by Canon PIXMA IP 1800 printer and underwent sintering temperature at $85 \%$ and $95 \%$ melting point of copper. The EDMed workpiece was aluminium and the electrodes surface was analyzed through scanning electron microscope (SEM). Findings showed that the electrode with $\mathrm{Cu}-0$ vol. $\% \mathrm{Al}_{2} \mathrm{O}_{3}$ composite and sintered at temperature $977{ }^{\circ} \mathrm{C}$ resulted in highest metal removal rate (MRR) and lowest electrode wear rate (EWR) while $\mathrm{Cu}-10$ vol. $\% \mathrm{Al}_{2} \mathrm{O}_{3}$ composite and sintered at temperature $977{ }^{\circ} \mathrm{C}$ revealed a better surface finish than other electrodes. An increase in $\mathrm{Al}_{2} \mathrm{O}_{3}$ content in general will increase the hardness of tool, as a trade-off, the conductivity was reduced.
\end{abstract}

\section{Introduction}

Electrical discharge machining (EDM) is a non-conventional machining process where material is removed electro thermally by a series of successive discrete discharges or sparks between two electrically conductive objects, which are electrode and workpiece. The

\footnotetext{
${ }^{1}$ Corresponding author: shazarel@uthm.edu.my
} 
hardness of the workpiece has no influence on the process capability. Material for EDM electrode must possess basic properties such as electrical and thermal conductivity, high melting temperature, low wear rate, and good resistance to deformation during machining [1].

The recent development in the field of EDM have progressed due to the growing application of EDM process and the challenges being faced by the modern manufacturing industries, from the development of new materials that are hard and difficult to machine such as tool steels, composites, ceramics, super alloys, hastalloy, nitralloy, waspalloy, nemonics, carbides, stainless steel, heat resistant steel, and etc. that being widely used in die and mould making industries, aerospace, aeronautics and nuclear industries. EDM is used extensively to produce cavities in hardened tool steel for molding plastics. Complex geometries or profiles can often be more easily machined on an electrode than in a cavity, making EDM viable in terms of lead time and quality of cut $[2,3]$.

In EDM, copper and graphite tools are commonly used as electrodes. Nevertheless, high tool wear is the major drawback of these electrodes for prolonged machining. The low wear resistance electrodes like $\mathrm{Cu}, \mathrm{Cu}$ alloys and graphite contribute problem in EDM operation. Increasing in the complexity of tooling for any EDM related operation results in a corresponding increase in time and costs required to develop such tooling.

Rapid prototyping (RP) is a process capable of fabricating prototype parts directly from three-dimensional CAD models [4]. One way to reduce time and to design tool with higher complexity in EDM is through rapid prototyping techniques. The techniques allow direct produced RP model used as an electrode for EDM. The tool should achieve greater metal removal rate with low tool wear characteristic. Multiple RP techniques such as StereoLithography (SL), fused deposition modeling, selective laser sintering, selective laser melting and $3 \mathrm{D}$ printing are possible to be adopted in the production environment of EDM tools fabrication.

Quite a lot investigations were devoted to study research related to metal powder added with ceramic materials to form a variety of composites. Study on sintering behavior of metal powder mixed with ceramic inclusions was also reported. The experiments were performed with mixtures of copper and alumina particles approximately with the same size and volume fractions of alumina between $5 \%$ and $30 \%$ are added together. Both experimental and simulation results on the effect of inert inclusions on the densification of metal-ceramic powder mixtures during free sintering was discussed. The densification was significantly delayed even for a volume fraction of inclusions as low as 5\% and strongly hindered when this content reached up to $20 \%$ [5]. Other than that, study on copper composites containing $\mathrm{O}-3 \mathrm{wt} \% \mathrm{Al}$ that were sintered in hydrogen at temperatures of $800^{\circ} \mathrm{C}$ and $900^{\circ} \mathrm{C}$ was investigated by [6]. The powders were prepared through the blending and mechanical alloying routes. The green compaction pressures were 500 and $560 \mathrm{MPa}$, respectively. Increasing in compaction pressure led to both sintered density and hardness increased. It was found that densification kinetics were faster for mechanically alloyed powder compacts than the blended ones. An increase in $\mathrm{Al}_{2} \mathrm{O}_{3}$ content in general increased hardness, with an associated loss in electrical conductivity.

Compounds of $\mathrm{ZrB} 2$ and TiSi with $\mathrm{Cu}$ at various compositions was also investigated for EDM electrodes by either using solid-state sintering or liquid phase sintering [4]. The performance of the newly formed material was compared with that of conventional electrode materials such as $\mathrm{Cu}$, Graphite and the rapid tool produced from the selective laser sintering (SLS). While, the manufacture of EDM electrode from rapid prototype pattern made by the stereolithography technique was studied by [7]. The model was a square cavity with inner dimensions of $80 \mathrm{~mm}$ by $80 \mathrm{~mm}$. A variety of features was added on the bottom face of this cavity. An SL pattern of the model was then successfully fabricated on the Stereolithography apparatus (SLA). 
In this study, composites of copper mixed with alumina at various compositions for EDM electrodes were investigated. The tools were fabricated using rapid prototyping (RP) in particular $3 \mathrm{D}$ printing technique with performed post processing. The study was aimed to develop EDM tool from composite material that should possess higher material remover rate (MRR), lower wear ratio (WR) and superior surface finish. The alumina particles are known hard and thermally stable at high temperature. It's mostly used in the production of aluminium, though it is also used as an abrasive material due to its hardness and as a refractory material due to its high melting point. Its hardness and ability to retain its elevated temperature properties are expected to make it suitable for application in EDM operation. In order to enhance bonding between copper and alumina, maltodextrin powder with melting point $240{ }^{\circ} \mathrm{C}$ was also mixed. The maltodextrin powder will be dissolved and act to bind the alumina and copper during the fabrication process. While water based binder was used to dissolve the maltodextrin during the $3 \mathrm{D}$ printing.

\section{Methodology}

\subsection{Material preparation}

Powder metallurgy method was used to fabricate the composite electrodes. Mixtures of copper, alumina and maltodextrin (act as binder) were used to fabricate the electrodes. Distinct compositions of composite mixture were considered as given in Table 1. The mean particle size and shape of the mixtures were also estimated. It was observed that the copper powder has a spherical shape and maltodextrin powder possessed a round shape while the alumina powder revealed an angular shape in the composite. The size of copper powder was approximately $30 \mu \mathrm{m}$ while both of alumina and maltodextrin powder were around 60 $\mu \mathrm{m}$. The mixture of powders were initially mixed in ball mill for 1 hour to achieve homogenization.

Table 1. Percentage mixture of $\mathrm{Cu}$ powder and $\mathrm{Al}_{2} \mathrm{O}_{3}$

\begin{tabular}{|c|c|c|c|}
\hline \multirow{2}{*}{$\begin{array}{l}\text { Sample } \\
\text { No. }\end{array}$} & \multicolumn{3}{|c|}{ Composition } \\
\hline & $\begin{array}{c}\text { Copper, } \mathrm{Cu} \\
(\%)\end{array}$ & $\begin{array}{c}\text { Alumina, } \mathrm{Al}_{2} \mathrm{O}_{3} \\
(\%)\end{array}$ & $\begin{array}{c}\text { Maltodextrin, } \\
(\%)\end{array}$ \\
\hline 1 & 100 & 0 & 10 \\
\hline 2 & 90 & 10 & 10 \\
\hline 3 & 80 & 20 & 10 \\
\hline
\end{tabular}

\subsection{Electrode preparation}

EDM electrodes were produced via Canon PIXMA IP 1800 printer which have been modified and has function similar to original 3D printer. The main reason of using this printer is to reduce the cost of material and printing. Figure 1 shows the microstructure of electrode before sinter. Sintering of the electrode was carried out in a tube furnace supplied with an argon gas. The temperature of sintering cycle is given in Figure 2. Sintering temperatures were set at two different levels. The temperature was first ramped to $400{ }^{\circ} \mathrm{C}$ to wipe out the binder (maltodextrin) and then raised to $874{ }^{\circ} \mathrm{C}$ and $977{ }^{\circ} \mathrm{C}$ respectively and stabilized for 4 hours. 


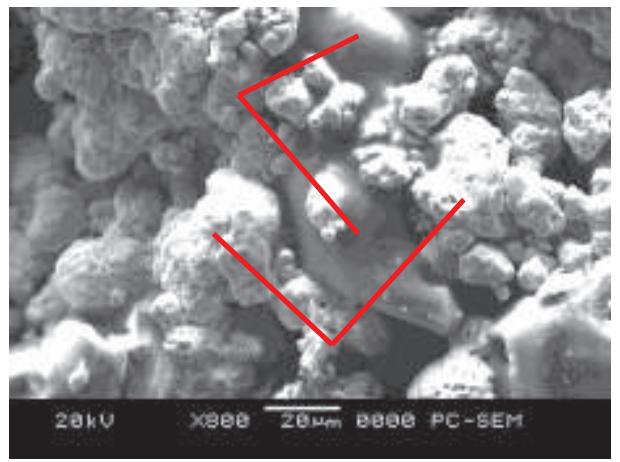

(a)

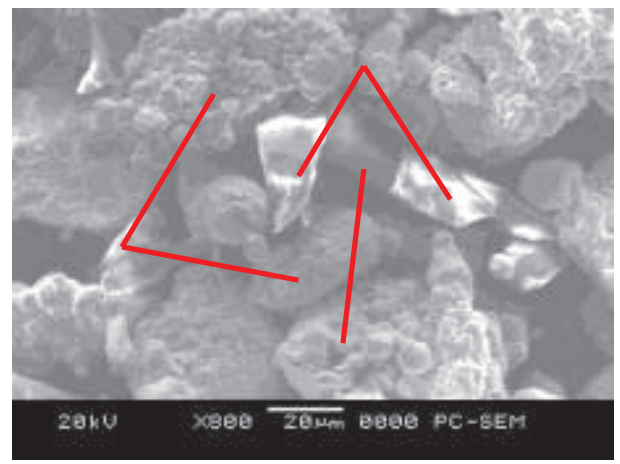

(b)

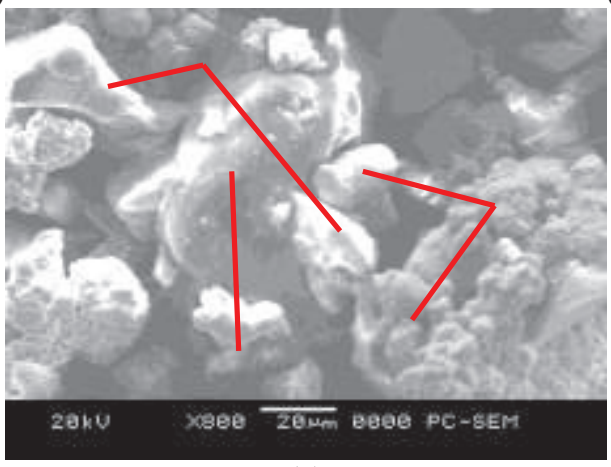

(c)

Fig. 1. The microstructure of electrode before sinter; (a) $100 \% \mathrm{Cu} / 10 \%$ Maltodextrin; (b) $90 \% \mathrm{Cu} /$ $10 \% \mathrm{Al}_{2} \mathrm{O}_{3} / 10 \%$ Maltodextrin; (c) $80 \% \mathrm{Cu} / 20 \% \mathrm{Al}_{2} \mathrm{O}_{3} / 10 \%$ Maltodextrin.

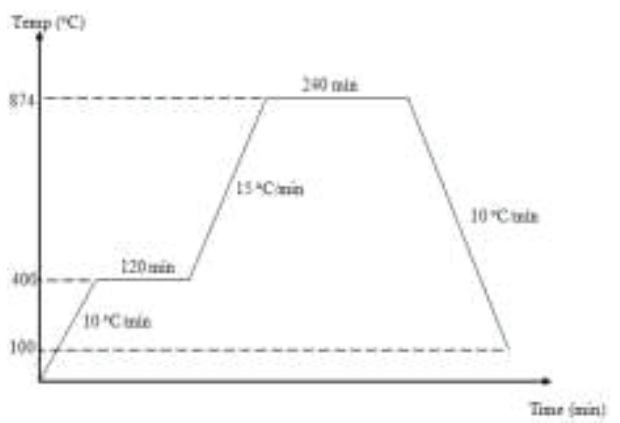

(a)

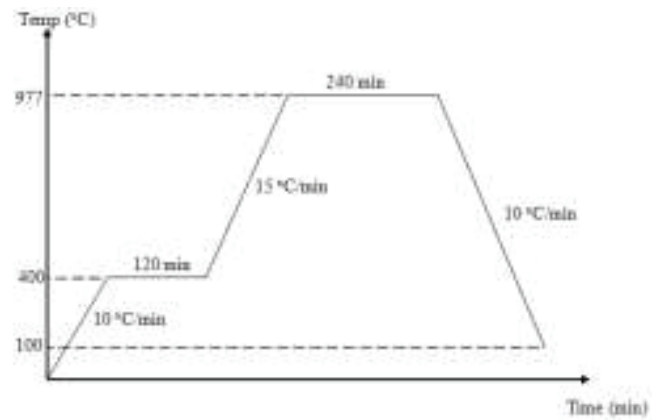

(b)

Fig. 2. a) Sintering cycle for $85 \%$, b) sintering cycle for $95 \%$ 


\section{Result and discussion}

\subsection{Microstructure}

Figure 3 and 4 show microstructure of sintered electrodes. During sintering, maltodextrin was gradually vaporized because of its low melting point characteristic compared to copper and alumina. The melting point of maltodextrin was $240{ }^{\circ} \mathrm{C}$ while both copper and alumina powder were around $1028{ }^{\circ} \mathrm{C}$ and $2000{ }^{\circ} \mathrm{C}$. The bonding was only took place among the copper powder and not visible within the alumina powder due to a huge different in melting temperature between both materials. The necking phenomena were only visible on copper particles and the boundary regions were created adjacent to copper inter-particles. It is also shows that more necking was visible at temperature $977{ }^{\circ} \mathrm{C}$. Nevertheless, the bonds strength of copper powder was insufficient to hold the alumina particles firmly. The high melting point of alumina causes an extreme temperature was needed to overcome its surface energy to allow necking to form. Due to this reason, the electrode becomes fragile and difficult to handle during the EDM process.

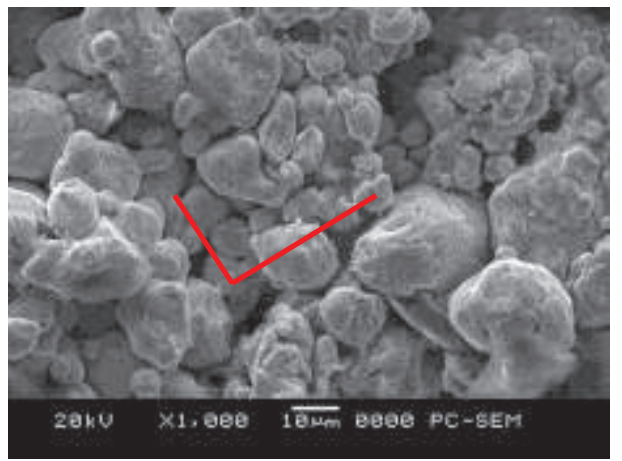

a)

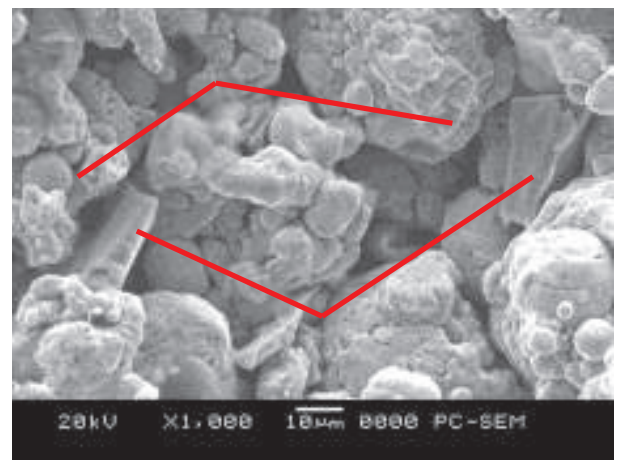

b)

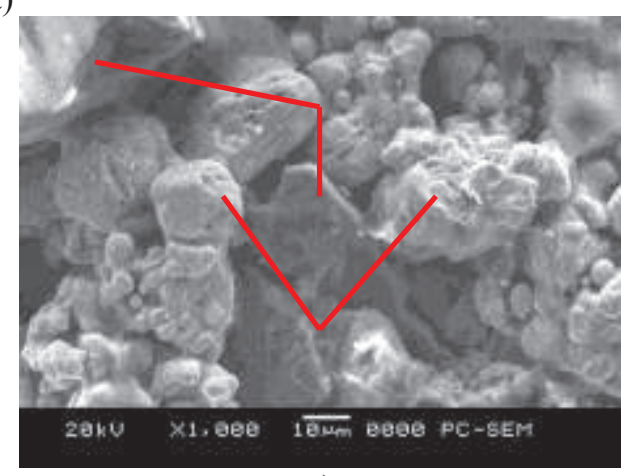

c)

Fig. 3. The microstructure of electrode after sintered at $874{ }^{\circ} \mathrm{C}$; (a) $100 \% \mathrm{Cu}$; (b) $90 \% \mathrm{Cu} / 10 \% \mathrm{Al}_{2} \mathrm{O}_{3}$; (c) $80 \% \mathrm{Cu} / 20 \% \mathrm{Al}_{2} \mathrm{O}_{3}$. 


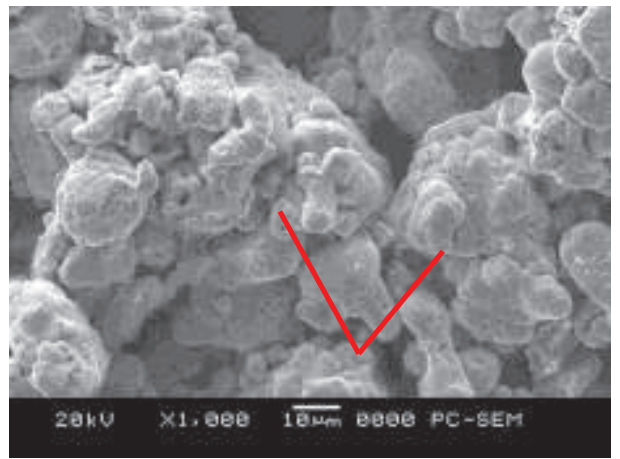

a)

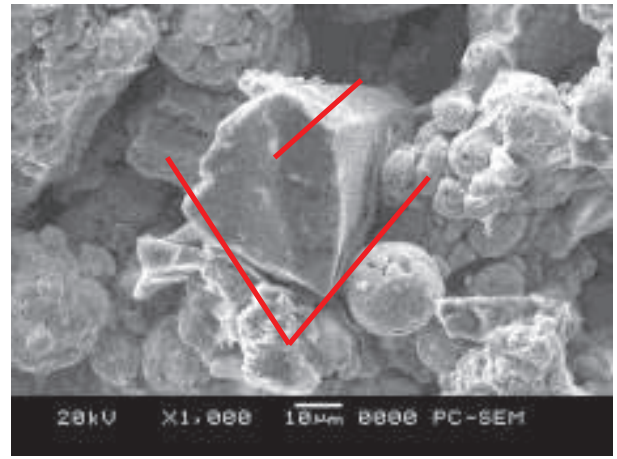

b)

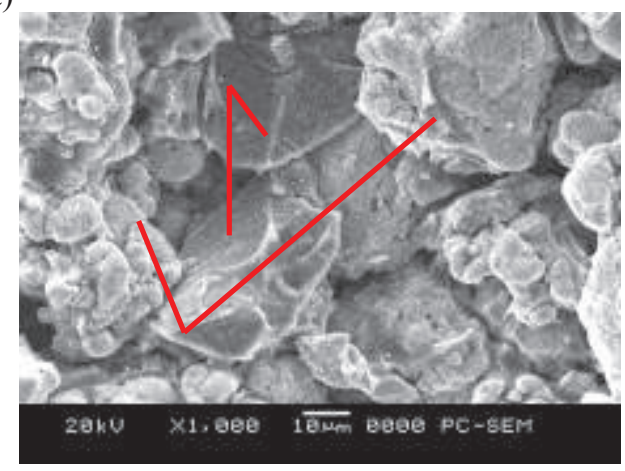

c)

Fig.4. The microstructure of electrode after sintered at $977^{\circ} \mathrm{C}$; (a) $100 \% \mathrm{Cu}$; (b) $90 \% \mathrm{Cu} / 10 \% \mathrm{Al}_{2} \mathrm{O}_{3}$; (c) $80 \% \mathrm{Cu} / 20 \% \mathrm{Al}_{2} \mathrm{O}_{3}$.

In all samples, the maltodextrin acts as a binder and used to hold temporarily the metallic compound during the $3 \mathrm{D}$ printing process. After sintering process, the binder vaporizes and this circumstance increases porosity in the fabricated electrode because the empty spaces left by the maltodextrin are not replaced immediately by the alumina and copper powders. As consequences, the porous samples that were already obtained after the electrodes fabrication via $3 \mathrm{D}$ printing become deteriorated.

\subsection{EDM tests}

The electrodes were tested for EDM and all parameters used in EDM was a default setting. Table 2 shows the parameters adopted for EDM. The machined workpiece was aluminium. Figure 5 and 6 show results of material removal rate and electrode wear rate at various material compositions.

Table 2. EDM Die-Sinking parameters.

\begin{tabular}{|c|c|c|c|c|c|}
\hline $\begin{array}{c}\text { Machining Time } \\
(\mathrm{sec})\end{array}$ & $\begin{array}{c}\text { Electrode } \\
\text { Polarity }\end{array}$ & $\begin{array}{c}\text { Ip } \\
(\mathrm{A})\end{array}$ & $\begin{array}{c}\text { Voltage } \\
(\mathrm{V})\end{array}$ & $\begin{array}{c}\text { Pulse On Time } \\
(\mu \mathrm{s})\end{array}$ & $\begin{array}{c}\text { Pulse Off Time } \\
(\mu \mathrm{s})\end{array}$ \\
\hline 300 & $+\mathrm{ve}$ & 5.4 & 60 & 86 & 43 \\
\hline
\end{tabular}




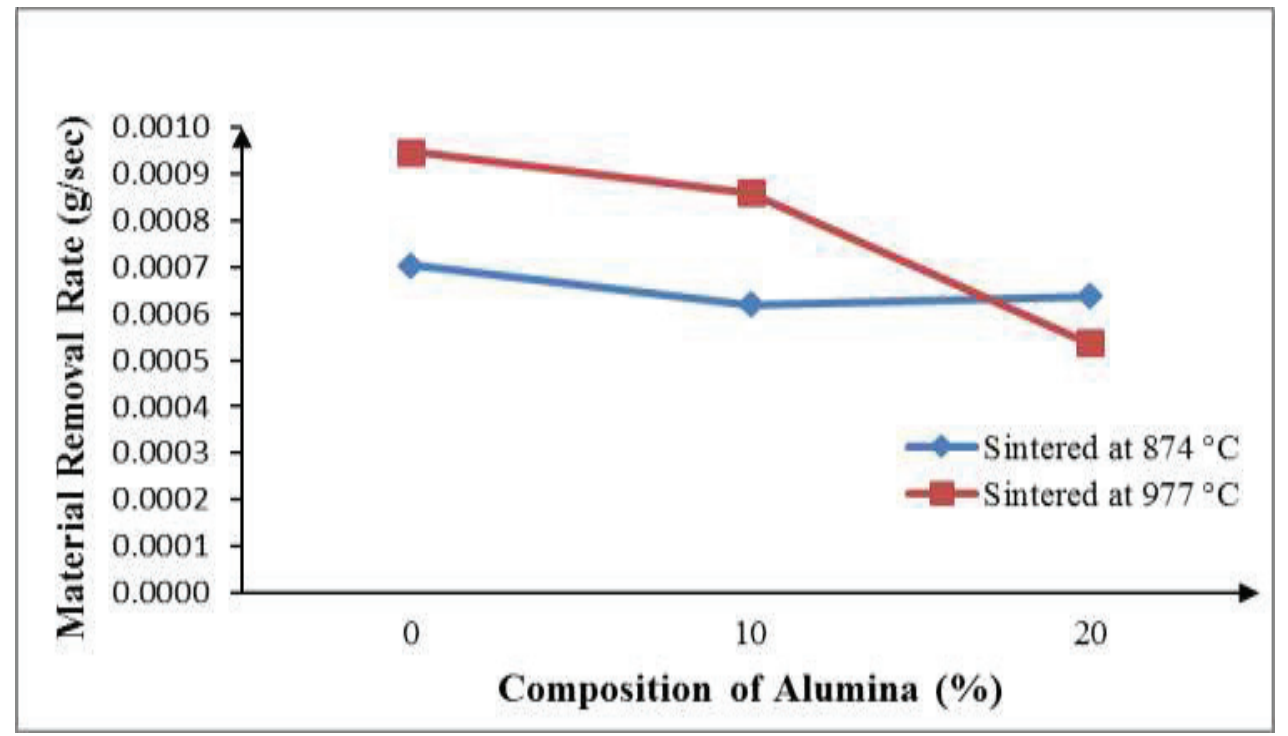

Fig. 5. Effect of different alumina compositions on material removal rate (MRR)

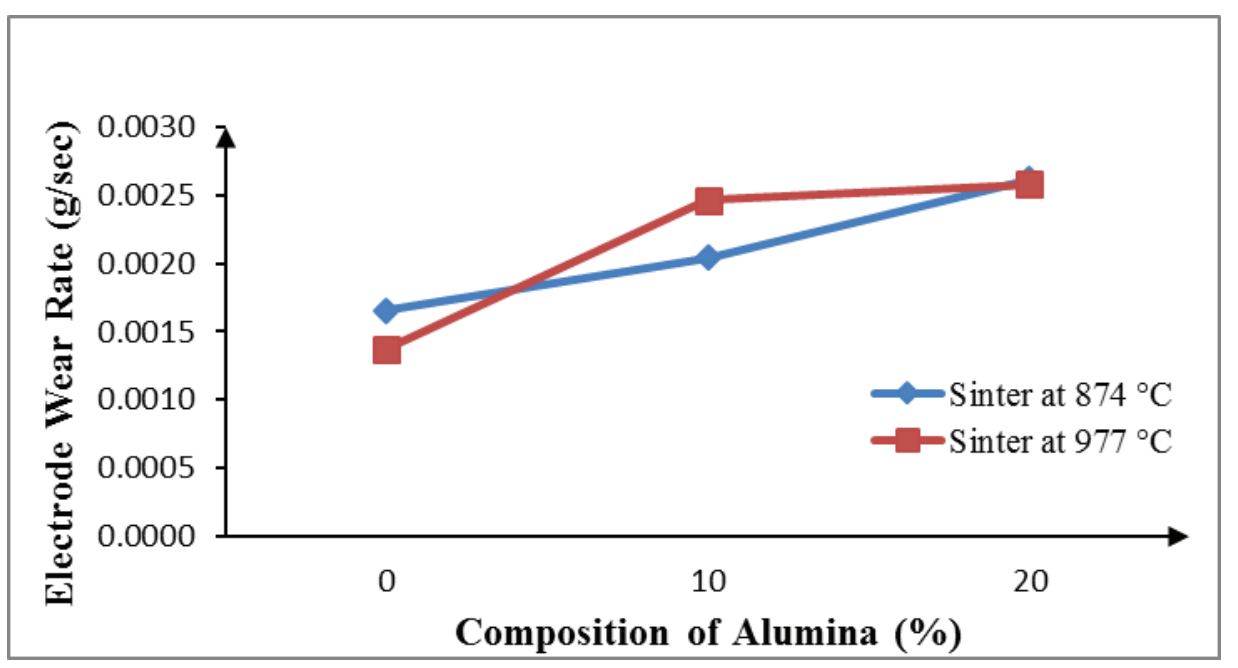

Fig. 6. Effect of various alumina compositions on electrode wear rate (EWR)

It is found that electrode with $\mathrm{Cu}-0$ vol. $\% \mathrm{Al}_{2} \mathrm{O}_{3}$ composite and is sintered at temperature $977{ }^{\circ} \mathrm{C}$ shows better metal removal rate (MRR) with less electrode wear rate (EWR), but it is beyond the acceptable level as EDM electrodes if compared to conventional electrode. This is due to poor inter-particle bonding between $\mathrm{Cu}$ and $\mathrm{Al}_{2} \mathrm{O}_{3}$. During the EDM process, the alumina is held poorly by the copper powders and the bonding among the metal powders loose easily. The composite unable to withstand high thermal stresses that counterattacked the bonding of particles before it's gradually melted by the spark erosion. Disruption on copper powders bonding by the existence of alumina powder contributed to the low thermal conductivity of the electrode. 
According to [3], for pure copper sample, most interparticle necks are well developed although their size is not uniform due to the random packing structure. For the composite with the lowest alumina content, the alumina particles appear to be isolated and less likely surrounded by the copper particles. It seems that many necks between copper particles in the close neighbourhood of an inclusion are less developed than the necks in pure copper specimen or the necks in the regions of the composites containing only copper particles, probably because of the constraint created by the presence of a rigid inclusion (alumina). Additionally, pores in the neighbourhood of an inclusion are noticeably larger than those inside a group of copper particles.

Besides, alumina is an electrical insulator but has a relatively high thermal conductivity. This will cause the MRR in EDM worsen when more alumina powder was mixed with the copper powder. The alumina will disturb the electrical and heat conductivity during the EDM process. The MRR proportional decreases with the accumulation of alumina compound in the electrode. According to [4], mechanically alloyed powder shows a progressive hardness increase with alumina addition better than powder that only underwent mixing and blending. Since hardening due to mechanical alloying imparts more scattering of electrons, thus it decreases the electrical conductivity and this is something not preferable in EDM. An increase in sintering temperature enhances thermal conductivity effectiveness in the respective composites. Figure 7 shows the effect of alumina on surface roughness.

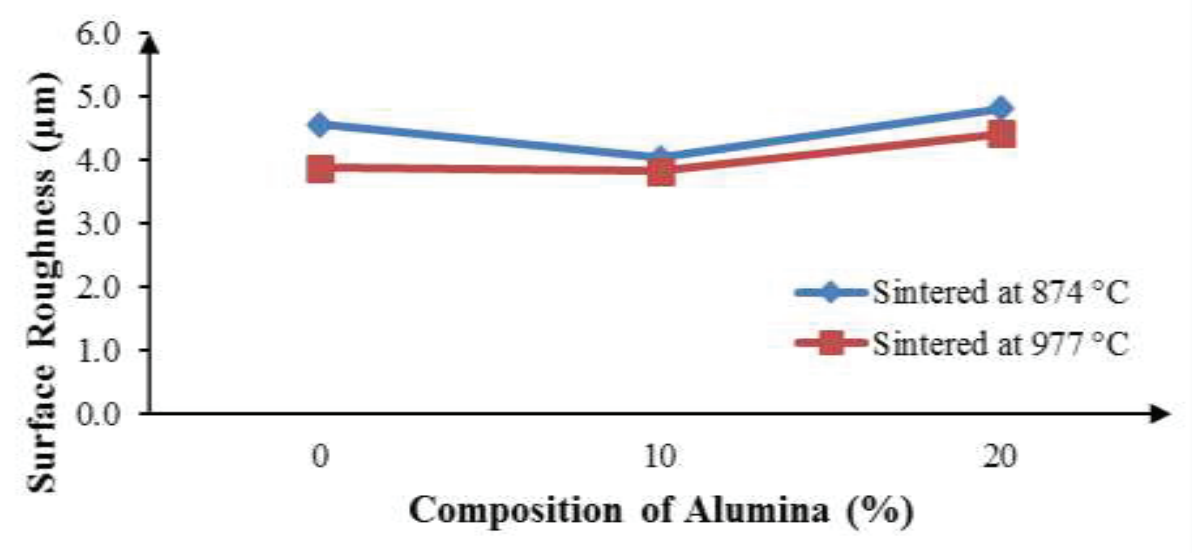

Fig. 7. Effect of Alumina on surface roughness, (Ra).

It was found that electrode with $\mathrm{Cu}-10$ vol. $\% \mathrm{Al}_{2} \mathrm{O}_{3}$ composite and sintered at temperature $977{ }^{\circ} \mathrm{C}$ shows better surface finish than other samples. From the findings, surface roughness increased with increasing the alumina powder. However, if the compound of alumina powder is mixed up in small quantity, the surface roughness of workpiece is better than pure copper tool. Alumina is the most widely used oxide ceramic, either in pure form or as raw material to be mixed with other oxides. If the percentage of alumina powder is too much, the surface roughness will increase due to intense spark formation between the tool and workpiece. According to [8], the application of voltage pulses causes electrical breakdown of the dielectric in a channel of radius $10 \mu \mathrm{m}$. The breakdown arises from the acceleration toward the anode of both electrons emitted from the cathode by the applied field and the stray electrons present in the gap. With an increase 
alumina content, more electrons collide with neutral atoms of the dielectric, thereby creating more positives ions and further electrons, which in turn, are accelerated towards and bombards the workpiece at larger capacity to cause a rougher surface creation.

\section{Conclusion}

The 3D printing technique introduced to fabricate the EDM tools in this study offers a great flexibility that makes the production of complex and intricate shape tools become much easier and faster. Based on the findings, it can be concluded that the electrodes produced by the $3 \mathrm{D}$ printing technique could have potential to be used in EDM die sinking, but further improvement is still required. It is due to the machining related performances known as the MRR is lower while the EWR and the surface roughness are higher compared to conventional electrodes. The results also show the electrode produced by $100 \%$ copper powder and sintered at $977{ }^{\circ} \mathrm{C}$ revealed the highest MRR and lowest EWR compared to other electrodes. For surface roughness, electrode with $90 \%$ copper powder and $10 \%$ of alumina and also sintered at $977^{\circ} \mathrm{C}$ was lower than other samples. It shows that $977^{\circ} \mathrm{C}$ is the best sintering temperature cycle and recommended for the $\mathrm{Cu}-\mathrm{Al}_{2} \mathrm{O}_{3}$ composite. High sintering temperature augments more inter-particle necking within the adjacent boundary of the copper particles. On top of that, in order to get a better machined surface, the alumina compound in the copper powder must be controlled. Improvement on the tool strength and EWR can be done by utilizing powder with spherical shape, reduce the powder size and embedding infiltration process with bronze during the post-processing stage.

\section{Ackowledgement}

The authors would like to express the deepest appreciation to the Office for Research, Innovation, Commercialization, Consultancy Management (ORICC), UTHM for funding this project and also partly supported by Sustainable Manufacturing and Recycling Technology, Advanced Manufacturing and Materials Center (SMART-AMMC), Universiti Tun Hussein Onn Malaysia (UTHM).

\section{References}

1. J. Kechagias, V. Iakovakis, M. Katsanos, S. Maropoulos, EDM electrode manufacture using rapid tooling: a review, Journal of Materials Science, 43(8), pp.2522-2535 (2008)

2. S. Singh, S. Maheshwari, P.C. Pandey, Some investigations into the electric discharge machining of hardened tool steel using different electrode materials, Journal of Materials Processing Technology, 149(1), pp.272-277 (2004)

3. A. Arthur, P.M. Dickens, R.C. Cobb, Using rapid prototyping to produce electrical discharge machining electrodes, Rapid Prototyping Journal, 2(1), pp.4-12 (1996)

4. H.M. Zaw, J.Y.H. Fuh, A.Y.C. Nee, L. Lu, Formation of a new EDM electrode material using sintering techniques, Journal of Materials Processing Technology, 89, pp.182-186 (1999)

5. L. Olmos, C.L. Martin, D. Bouvard, Sintering of mixtures of powders: Experiments and modelling, Powder Technology, 190(1), pp.134-140 (2009) 
6. A. Upadhyaya, G.S. Upadhyaya, Sintering of copper-alumina composites through blending and mechanical alloying powder metallurgy routes, Materials \& Design, 16(1), pp.41-45 (1995)

7. P.K. Yarlagadda, P. Christodoulou, V.S. Subramanian, Feasibility studies on the production of electro-discharge machining electrodes with rapid prototyping and the electroforming process, Journal of Materials Processing Technology, 89, pp.231-237 (1999)

8. Hasan El-Hofy, Fundamentals of Machining Processes, Taylor \& Francis, New York, pp.371-383 (2007)

9. J.A McGeough, P. Regius, Advanced Method of Machining, London New York: Chapman and Hall, pp133-144 (1998)

10. S. Kalpakjian, S.R. Schmid, Manufacturing Engineering and Technology $4^{\text {th }}$.ed., New Jersey: Prentice Hall, Inc., pp.148-149, 873-875 (2001) 